HUMANAS E SOCIAIS

V.8 • N.3 • 2020 • Fluxo Contínuo

ISSN Digital: 2316-3801

ISSN Impresso: 2316-3348

DOI: 10.17564/2316-3801.2019v8n3p405-421
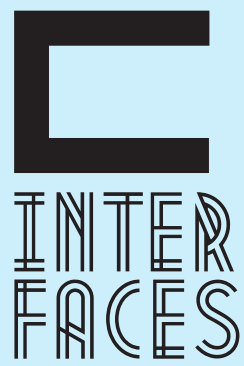

CIENTÍFICAS

\section{QUESTÕESE CONTRADICÕES DO PROGRAMA MCMV: ANÁLISE NACIONAL DA POLÍTICA PÚBLICA ENTRE 2009 E 2013}

MCMV PROGRAM ISSUES AND CONTRADITIONS: 2009-2013 NATIONAL PUBLIC POLICY REVIEW

PROBLEMAS Y CONTRADICIONES DEL PROGRAMA MCMV: REVISIÓN DE POLÍTICAS PÚBLICAS NACIONALES 2009-2013

Naiara Sandi Almeida Alcantara 


\section{ABSTRACT}

In this article, it was realized a quantitative analysis of secondary data of the MCMV public policy, between 2009 and 2013, through the manipulation of the database of the Satisfaction Survey of the My Home My Life Program, launched by the Ministry of Cities (MCIDADES), National Secretariat of Housing (SNH) and Institute of Applied Economic Research (IPEA), which is representative of all Brazil. The interviews were composed of structured questionnaires. The objective of this study was to develop an analysis of MCMV using as a parameter the quality of urban life and the housing deficit. As a secondary objective, an analysis of housing policies prior to the MCMV was carried out. The results showed that there is no permanence of the conditions that make up the housing deficit, but the beneficiaries have a poor quality of urban life.

\section{KEYWORDS}

Urban Quality of Life. Housing Policy. Housing deficit.

\section{RESUMEN}

En este artículo, se realizó un análisis cuantitativo de los datos secundarios de políticas públicas MCMV entre 2009 y 2013, a través de la manipulación de la base de datos de la Encuesta de Satisfacción de los beneficiarios del programa Programa Minha Casa Minha Vida, lanzado por el Ministerio de Ciudades (MCIDADES), Secretaría Nacional de Vivienda (SNH) e Instituto de Investigación Económica Aplicada (IPEA), compuesto por muestras representativas de todo Brasil. Las entrevistas consistieron en cuestionarios estructurados. El objetivo fue desarrollar un análisis de la MCMV utilizando como parámetro la calidad de vida urbana y el déficit habitacional. Como objetivo secundario, se realizó un análisis de las políticas de vivienda antes de la MCMV. Los resultados mostraron que no hay permanencia de las condiciones que conforman el déficit habitacional, sin embargo, los beneficiarios tienen una baja calidad de vida urbana.

\section{PALABRAS CLAVE}

Calidad de vida urbana. Política de vivienda. Déficit habitacional. 


\section{INTRODUÇ̧̃̃o}

O espaço urbano no Brasil é composto por um cenário de larga desigualdade social e de difícil acesso a necessidades essenciais para a perpetuação e renovação da força de trabalho, que advêm da desigualdade econômica e se reverbera na falta de acesso à moradia e de todos os outros equipamentos e serviços públicos como: saúde, educação, mobilidade etc., trazendo a lume a iminente necessidade das políticas públicas como meio de efetivação dos direitos presentes nos dispositivos legais, especialmente a partir do início do século $\mathrm{XX}$, período em que os processos de inchamento dos aglomerados urbanos tomam expressão e podem ser percebidos na divisão da área urbana (BONDUKI, 2004; MARICATO, 2000).

Por isso será apresentado um breve histórico das políticas habitacionais anteriores ao Programa Minha Casa Minha Vida (PMCMV), que permitirá inferir se esse programa apresenta resultados semelhantes aos seus precursores. Estudando o cenário histórico do país, verificou-se que as primeiras políticas habitacionais começaram a ser implementadas a partir do governo Vargas.

Mediante a necessidade de movimentação de setores privados, como de construção civil, é que se cria a Lei do Inquilinato (1942), os Institutos de Aposentadoria e Pensão (IAP-1930), a Fundação Casa Popular (FCP-1946), o Banco Nacional de Habitacional (BNH-1964), o Sistema Financeiro de Habitação (SFH-1964), dentre outros mecanismos de política habitacional no país, que serão descritos detalhadamente. Essas leis, programas e propostas eram distintos entre si, contudo, todos possuíam como finalidade facultar o acesso à habitação para a população pobre.

À vista disso, apresentavam consequências também distintas, todavia alguns resultados eram comuns a todos, como as taxas de inadimplência dos aluguéis ou prestações das casas, que variavam entre os programas, mas mantendo sempre a existência de moradores que não possuíam renda suficiente para permanecer na moradia. Além disso, os programas com menores taxas de inadimplência eram também aqueles que não contemplavam as camadas sociais mais baixas. Em todos se constatou que a população em maior vulnerabilidade social era a que recebia a menor quantidade de casas.

0 crescente surgimento de habitações precárias, assim como a ineficiência das políticas criadas para a resolução do problema habitacional, desemboca no início do século XXI, em um elevado índice de déficit habitacional, com mais de 7 milhões de famílias, residindo de maneira precária. Contudo, foi somente após a incidência da chamada crise do subprimes que teve início nos Estados Unidos em 2007 e começou a afetar a economia nacional em 2008, que foi criado, em 2009, o MCMV, um programa que possuía como meta inicial a construção de 1 milhão de Unidades Habitacionais (UH) e movimentaria diversos setores da economia nacional (AMORE, 2015).

A partir das considerações realizadas sobre o MCMV, sua inserção na agenda pública e implementação em 2009, este artigo busca verificar se o programa está modificando a vida da população ou se, após o recebimento das casas elas permanecem em situação semelhante à que se encontravam antes, por meio da análise das condições que compõe o índice do déficit habitacional e, ainda, se os moradores tiveram acesso à qualidade de vida urbana, pela análise da: i) qualidade de habitação; ii) qualidade urbana e iii) vulnerabilidade social. 
Por meio da utilização da pesquisa quantitativa, realizou-se a manipulação dos dados secundários do banco de dados da Pesquisa de Satisfação dos beneficiários do Programa Minha Casa Minha Vida (2014)2, trata-se de uma pesquisa de amostragem nacional, aplicada em todo o país no segundo semestre de 2013 a famílias que residiam há pelo menos seis meses nas Unidades Habitacionais (UH) do faixa 1 do programa. A pesquisa foi financiada e os questionários aplicados por profissionais do Ministério das Cidades (MCIDADES), Secretaria Nacional de Habitação (SNH) e Instituto de Pesquisa Econômica Aplicada (IPEA).

Utilizou-se como parâmetro de análise a qualidade de vida urbana ${ }^{3}$ e o índice de déficit habitacional elaborado pela Fundação João Pinheiro (FJP), que pode ser sintetizadas pela identificação de: a) Domicílios precários (rústicos ou improvisados); b) Coabitação forçada, aquela na qual a família convivente deseja constituir novo domicílio, mas não possui condições necessárias para tal; c) Famílias que residem em imóveis locados, com valores que comprometem $30 \%$ da renda familiar; d) Adensamento excessivo em imóveis locados, onde existem 3 ou mais moradores, utilizando um cômodo como dormitório permanente. Como a condição "a” enquadra-se em reposição de estoque, a análise do banco de dados de 2014 irá repousar somente sobre as 3 últimas condições. Para responder a cada uma dessas condições, serão selecionadas todas as variáveis de interesse.

\section{HISTÓRICO DAS POLÍTICAS HABITACIONAIS NO BRASIL DAS DÉCADAS 1930 A 1990}

A habitação somente passou a ser interpretada pelo poder público como essencial ao proletário, inclusive como estratégia de aumento da produção industrial, a partir de governos nacionais desenvolvimentistas, que no Brasil teve início na Era Vargas, pois é somente nesse período que se instaura a primeira crise de moradia. Esse governo pretendia modificar as ideologias que permeavam o imaginário popular, e a habitação social era uma forma de fazer surgir no trabalhador ideários políticos (BONDUKI, 2004).

Assim sendo, em 1942 foi criada a Lei do Inquilinato, que congelava todos os aluguéis. Essa lei além de não resolver o problema habitacional aumentou o déficit porque houve uma redução nos investimentos do excedente na construção do parque residencial, que foi deslocado para o investimento na industrialização. Além disso, deu ensejo ao surgimento das favelas nas grandes cidades, porque os proprietários não podiam, legalmente, aumentar os preços dos aluguéis, contudo, utilizavam de todo tipo de artimanha para cobrar outras taxas que gerassem lucro, ou então utilizavam uma ordem de despejo para reaver os domicílios (BONDUKI, 2004).

Dentre as várias possibilidades para resolver a questão da habitação, a propriedade da casa mostrava ser a opção que geraria maiores ganhos ao trabalhador que seria dono de sua moradia, pois “[...] a casa salubre suburbana difunde-se como símbolo de bem-estar urbano [...]”; o planejamento dessa

2 Agradecemos a coordenadora executiva da pesquisa da Secretaria Nacional de Habitação, Angélia Amélia Soares Faddoul, pelo fornecimento do banco de dados da pesquisa utilizada, já que esses dados não estão disponíveis de maneira pública.

3 Apesar de ser um termo bastante abstrato, selecionou-se variáveis que puderam ser utilizadas para definir e corporificar o termo, portanto, foram escolhidas variáveis que se enquadram na qualidade da habitação urbana e vulnerabilidade social. Foram utilizadas todas as variáveis do banco que acreditava-se dar densidade ao conceito. 
nova forma de morar adquirida por menores valores do que aquele imposto pelo mercado ocorreu somente distante dos centros e o principal problema era a falta de todo tipo de equipamentos públicos e serviços básicos (BONDUKI, 2004; LAGO, 2017, p. 141).

Durante o governo Vargas, os primeiros órgãos que se destinaram a construção de casas populares foram os Institutos de Aposentadoria e Pensão (IAP) criados em 1930, por meio deles se iniciou a construção de casas populares, todavia, logo demonstrou ser uma política fragmentada que não atingiu a maior parte da população. Posteriormente, em 1946, surge a Fundação Casa Popular (FCP) que dependia em grande parte do auxílio do governo federal e, por isso, conforme as gestões mudaram, modificavam-se também as verbas recebidas, portanto pouco do que a política previa teoricamente foi executado e a abrangência do FCP foi muito diminuta em relação ao que se esperava inicialmente (AZEVEDO, 1988).

Em 1964 foi criado o Sistema Financeiro de Habitação (SFH), composto pelo Banco Nacional de Habitação (BNH) e a Sociedade de Crédito Imobiliário. O BNH pretendia solucionar o problema habitacional por meio da criação e acesso à moradia popular, que por sua vez está incumbida de dois principais simbolismos: o subjetivo, de levar as pessoas a ascender financeiramente na sociedade capitalista e o objetivo, de minimização dos gastos mensais em moradias alugadas.

Por meio dos investimentos advindos do Fundo de Garantia por Tempo de Serviço (FGTS), o BNH torna-se um dos maiores bancos do Brasil. Essa estratégia política pretendia, sobretudo, amenizar a insatisfação das massas, para que essa camada social não se pusesse contra a gestão militar (CARVALHO, 1991; BOLAFFI, 1979; MARICATO, 1987).

Após seis anos de criação do BNH, a política habitacional havia atendido somente $24 \%$ das famílias em situação de déficit habitacional. Segundo Azevedo (2002), o BNH funcionou como um “Robin Hood” às avessas na medida em que o valor repassado ao banco era descontado do Fundo de Garantia por tempo de Serviço (FGTS) de todos os trabalhadores com carteira assinada, inclusive os mais pobres, entretanto as camadas sociais que mais receberam casas eram as médias e altas (AZEVEDO, 2002, p. 58; MARICATO, 2000, p. 3).

Em 1973, é criado o que Maricato considera como tentativas de recuperação do BNH e do SFH: o Plano Nacional de Habitação Popular (PLANHAP) e o Sistema Financeiro de Habitação (SIFHAP). Ambos foram criados com a tentativa de, ao recapitular as premissas bases dos programas anteriores, ou seja, criação de moradia popular, combate ao Déficit Habitacional e, primordialmente o desenvolvimento econômico do país, por intermédio, do fomento da indústria de construção civil, não repetindo os erros dos projetos anteriores.

Criou-se, também, a Companhia Metropolitana de Habitação de São Paulo (COHAB-SP), em 1965, para atender a camada populacional que possuísse renda de 0 a 3 salários mínimos, em uma década criou quase 10 mil Unidades Habitacionais (UH), contudo, mais de $50 \%$ das construções não foram concluídas e começaram a se deteriorar (MARICATO, 1987, p. 43).

Segundo Aragão e outros autores (2017) após os programas supramencionados o país passou por um longo período sem inclusões de políticas públicas habitacionais no cenário político, até o momento em que Fernando Henrique Cardoso assume a presidência do país em 1995, tomando medidas de financiamentos habitacionais de baixa renda. Todavia as adversidades causadas pelo câmbio e queda do real influenciaram diretamente nos investimentos habitacionais, somados a isso o endividamento do setor público, acabaram levando a estagnação do programa que ainda estava em fase inicial, o Pró-moradia. 
Como alternativa ao problema em 1999 é criado o Programa de Arrendamento Residencial (PAR), que posteriormente será utilizado como base para a criação dos programas dos governos petistas de Luiz Inácio Lula da Silva e de Dilma Rousseff. O PAR era voltado ao atendimento de famílias que possuíam entre 3 e 6 salários mínimos, por isso criou-se, em 2001, o Programa de Subsídio Habitacional voltado a famílias com renda bruta mensal de 1 a 3 salários. Sem embargo, esses programas apresentaram baixo rendimento em relação as metas iniciais, o PAR, por exemplo, havia construído 106 mil UH até o ano de 2003 (ARAGÃO, 2017 apud BONDUKI, 2008).

\section{PROGRAMA MCMV E A CRISE DO SUBPRIMES}

A partir da retomada histórica das políticas anteriores ao MCMV, é possível demonstrar que esse programa surge como forma de combate direto a crise do subprimes e do déficit habitacional, em 2009, posteriormente o programa constitui-se como política habitacional, movimentando diversos setores da economia e elevando o poder de consumo da classe baixa, fazendo com que o Produto Interno Bruto (PIB) voltasse a crescer. "[...] o Programa buscava claramente aquecer o mercado imobiliário de unidades novas e, assim, impactar a economia através dos efeitos multiplicadores gerados pela indústria de construção civil” (ARAGÃO, 2017, p. 29).

Além do programa MCMV criaram-se também outros subsídios para que as famílias mais pobres conseguissem comprar uma UH, como o aumento de crédito, do salário mínimo, a efetivação do Fundo Garantidor de Habitação (FGH), que funcionava como um seguro em alguma eventualidade (como a perca do emprego). Segundo Aragão (2017), agindo dessa maneira o MCMV retoma os mesmos princípios do BNH voltado ao crescimento econômico e geração de emprego (ARAGÃO, 2017).

Logo, o MCMV surge da iniciativa do setor privado da construção civil, que previa a geração de emprego em diversos setores, bem como, a movimentação das mais diversas indústrias, inclusive a de móveis e eletrodomésticos, após a entrega das UH. Os problemas relacionados ao programa começam a surgir desde o planejamento das metas iniciais, como em relação à quantidade de casas destinadas a camada social que mais necessita de habitação, que são famílias que possuem renda de até 3 (três) salários mínimos, sendo que essa população compunha $90 \%$ do Déficit Habitacional. A previsão de construção era de 1 milhão de casas, sendo que somente 400 mil seriam destinadas a faixa 1 (um) (0-3 salários). Arantes e Fix (2009, p. 24) pontuam que:

0 problema da moradia é real e talvez seja um dos mais importantes no Brasil.

Contudo o "Minha Casa, Minha Vida" o formula falsamente, não a partir das características intrínsecas ao problema, mas sim das necessidades impostas pelas estratégias de poder, dos negócios e das ideologias dominantes - como já afirmou o sociólogo Gabriel Bolaffi em sua interpretação certeira sobre o BNH.

Esse excerto corrobora com a discussão que põe em dúvida a real motivação do programa, pois as famílias que mais precisam da política pública compõem o conjunto de $90 \%$ do Déficit Habitacional 
brasileiro, todavia, a previsão inicial de construção só destinava $40 \%$ das moradias para essa população. Aragão e outros autores (2017) apresenta um cenário oposto, demonstrando que o programa resultou no auxílio da superação da crise, pois aumentou o poder de consumo popular, gerou empregos e, primordialmente, possibilitou o acesso à habitação a camada social que historicamente mais necessitava. Portanto, o segundo mandato do governo Lula se encerra bastante positivo, apesar dessa informação não ser de consenso (ARAGÃO, 2017, p. 30).

Pois, Fix (2011) ainda demonstra que o MCMV não se propôs a enfrentar diretamente o problema fundiário e que nenhuma política pública habitacional seria eficaz no sentido de possibilitar moradia às camadas sociais que mais necessitam sem antes enfrentar a mercantilização da terra, pois o modelo do programa como foi implementado para o faixa 1 ( 0 a 3 salários mínimos) influenciaria a construção de Unidades Habitacionais (UH) nos locais mais distantes do centro ou nas áreas rurais que fariam a transição para o perímetro urbano, acarretando maior ônus ao poder público que teria que arcar com toda a infraestrutura. Isto posto, depreende-se que a construção das cidades ocorre com certo planejamento urbano, seguindo alguns critérios de organização que, todavia, não são aqueles que poderiam beneficiar os residentes, especialmente os mais pobres.

\section{PESQUISA DE SATISFAÇÃO DOS BENEFICIÁRIOS DO MCMV}

O objetivo principal do artigo, partindo da definição acima alinhavada sobre o MCMV, foi desenvolver uma análise em relação à manutenção das características de déficit habitacional e de qualidade de vida urbana, por meio da manipulação e análise dos dados secundários da Pesquisa de Satisfação dos beneficiários do $M C M V^{4}$. Sua descrição pormenorizada será feita a seguir, para verificar se existe uma porcentagem significativa de famílias beneficiárias do PMCMV que permanecem em situação análoga a, no mínimo, uma das condições que compõe o déficit habitacional ${ }^{5}$, e para analisar a qualidade de vida urbana na nova casa.

\footnotetext{
4 Essa pesquisa realizou um monitoramento da política habitacional do PMCMV em todo o Brasil, avaliando a satisfação dos beneficiários, todavia, não foi uma avalição que pretendeu discutir a eficácia, efetividade e eficiência da política.

5 Bolaffi no artigo Habitação e urbanismo: o problema e o falso problema (1979) ressalta que fez parte da conjuntura política adotada a criação de um falso problema que fora articulado pelos dominantes, e denominado como déficit habitacional. Então os problemas sociais e a resolução dos mesmos variam de acordo com o grupo político que está no poder. Isso não significa que não houvesse reais problemas de moradias precárias e carência de habitação, mas que havia manipulação da forma como eram tratados, sob a justificativa de manutenção no poder. Estudando sobre a forma como se formula falsamente o problema habitacional é possível indagar o papel do conceito, formulado pelo Estado, chamado de déficit habitacional elaborado pela Fundação João Pinheiro (FJP) a partir de uma demanda do Governo Federal em meados da década de 1990 (ARAGÃO et al., 2017). Segundo Bolaffi (1979, p. 52) esse termo pode ser definido como “[...] um conceito totalmente espúrio e destituído de significado [...]", interpretado dessa forma, quando utilizado como argumento para a criação de uma política pública de habitação, mas que não tinha reais intenções de combater o problema habitacional. Então o próprio déficit seria uma estratégia falsa de governo, formulada para responder as demandas dos setores econômicos. Elegendo a habitação como problema principal, seria plausível utilizar todas as estratégias econômicas para solucioná-la, relegando a último plano outras carências mais urgentes e, também de primeira necessidade como alimentação e saúde.
} 
Importante destacar que estar compondo o índice de déficit habitacional é um dos critérios exigidos pelas regras do MCMV para o recebimento da Unidade Habitacional (UH). Ou seja, os indivíduos recebem a moradia do programa e, por isso, deixam de fazer parte do índice de déficit habitacional. Dessa forma, o índice diminui, entretanto, a condição de vida da família pode permanecer precária. Utilizou-se para análise da qualidade de vida urbana dos beneficiários: a qualidade da habitação que está relacionado à estrutura física da casa e tempo gasto de locomoção diário; a qualidade urbana ao acesso à infraestrutura e equipamentos públicos e serviços básicos; e vulnerabilidade à violência no local de moradia.

Apesar das críticas que possam ser levantadas em relação ao déficit habitacional, como as expostas na nota de rodapé n. 6 , não significa que como medidor de condições precárias de moradia o déficit possa ser descartado, mas que somente em uma gestão que pretenda primordialmente a diminuição das desigualdades, que esse mecanismo estará de acordo com suas formulações teóricas. Por ser um método de medição que pode ser aplicado e é utilizado para a formulação das políticas habitacionais, ele é utilizado neste artigo.

Para o desenvolvimento da metodologia escolhida, é necessário salientar que o MCMV era composto, no período da pesquisa (2013), por 3 (três) faixas salariais: faixa 1 possui maiores financiamento que pode chegar a $90 \%$ e é composto por famílias que recebem até três salários mínimos (R\$1.600,00); as outras duas faixas, do mesmo modo, possuem auxílio do Governo Federal, por intermédio da diminuição das taxas de juros e outras concessões, são formadas por famílias que recebem de três a seis salários mínimos $(R \$ 3.275,00)$ para o faixa 2 e de seis a nove salários mínimos $(R \$ 5.000,00)$ para o faixa 3.

Como o banco de dados é datado, os valores apresentados são referentes ao salário mínimo da época ${ }^{6}$. 0 banco representa uma avaliação amostral de todo o Brasil cujo universo é composto por 245.205 Unidades Habitacionais (UH), até o ano de 2013. A partir desse universo o cálculo amostral demonstrou que $7.252 \mathrm{UH}$, seria uma quantidade representativa. Para a seleção da amostra definida foram realizadas algumas estratificações. A primeira dividiu as Unidades Federativas (UF) em 16 áreas, levando em consideração a quantidade dos conjuntos habitacionais e o tamanho deles. Dentro de cada uma dessas áreas utilizou-se outra forma de divisão, levando em consideração o tamanho dos conjuntos, a saber: conjuntos de pequeno, médio e grande porte?

Para a realização da pesquisa utilizou-se de entrevistas com questionários estruturados, que foram aplicados no segundo semestre de 2013, para famílias que estavam residindo há no mínimo seis meses nas UH. Esse tempo foi considerado suficiente para a criação do primeiro conjunto de percepções acerca da moradia e serviços no entorno, para que assim os moradores pudessem responder com maior confiança a todas as questões. A análise descritiva da pesquisa foi lançada em $2014^{8}$ e contêm dados referentes ao lapso temporal de 5 anos desde a implementação da política. Dessa forma, se teceu inferências a partir da manipulação do banco de dados, composto por uma amostra representativa do MCMV em todo o país, referente ao intervalo de tempo de meia década desde a criação do programa.

6 Alguns anos depois da publicação houve a criação de uma faixa intermediária entre as três já existentes e, além disso, houve alguns reajustes no salário mínimo. Sem embargo, como a pesquisa restringiu-se a investigação do faixa 1, por se tratar da faixa com maiores subsídios e os valores utilizados serão todos da época da pesquisa, utilizar-se-á os dados originais 70 primeiro agregava até $419 \mathrm{UH}$, o segundo de 420 a $960 \mathrm{UH}$ e o terceiro todos os conjuntos com mais de $961 \mathrm{UH}$. 8 E está referenciada no final do trabalho, sendo que nas últimas páginas da análise descritiva consta o questionário aplicado. 
Para responder se o beneficiário do MCMV permanece em situação análoga a que estavam antes do recebimento da moradia, utilizou-se variáveis selecionadas do banco (2014). Sabe-se que a primeira condição do déficit (condição “a”- domicílio precário) foi sanado pelo programa, afinal as famílias não se encontram mais em casas rústicas ou improvisadas, já que a construção das moradias do MCMV segue alguns parâmetros legais básicos de construção, destarte a reposição de estoque não será investigada. A (condição b) "Coabitação forçada" foi avaliada a partir da variável 042 "Quantas famílias residem no seu domicílio atual?” e 077 “Nós pretendemos mudar dessa moradia nos próximos meses”. A partir dessas questões, foi possível verificar quantas famílias estão em condição de coabitação.

Para investigar a (condição c) “Famílias que residem em imóveis locados, com valores que comprometem $30 \%$ da renda familiar", observou-se a variável 017 que questiona sobre a renda bruta familiar mensal e, depois a V055 "Qual é o gasto médio mensal com a prestação ou aluguel no domicílio atual”, dessa forma, foi possível verificar se os gastos mensais comprometem $30 \%$ ou mais da renda familiar bruta mensal.

Também se averiguou a variável 054 "Qual o gasto médio mensal com água, luz e condomínio, se for o caso no domicílio atual”, porque apesar da condição se referir somente ao valor do aluguel, o morador que recebe casas em condomínios verticalizados terá um gasto que talvez não tivesse na situação anterior, relativa à taxa que tem como finalidade custear a manutenção de todos os serviços comuns, por ser uma conta fixa e sua inadimplência acarretar punições previamente acordadas entre os condôminos ou de acordo com o Código Civil, art. 1.335, § 1: "O condômino que não pagar a sua contribuição ficará sujeito aos juros moratórios convencionados ou, não sendo previstos, os de um por cento ao mês e multa de até dois por cento sobre o débito".

Portanto, o não pagamento dos valores cobrados pode somar-se aos fatores de abandono ou desejo de mudanças das UH, pois representam o acúmulo de dívidas. Apesar de a condição "c" prevista no déficit habitacional averiguar somente o valor gasto com aluguel, por considerar que o dispêndio de uma grande parte da renda familiar para o pagamento mensal da moradia relega aos moradores a uma condição de vulnerabilidade social, por fatores como: cobrança judicial da dívida que pode acarretar na perda de bens (quando houver) ou valores quando assim julgado e diminuição do poder aquisitivo para compra de bens de primeira necessidade como alimentação, vestimenta, saúde e afins.

Como o não pagamento do condomínio pode acarretar sanções idênticas ao não pagamento do aluguel, esse trabalho sugere que os valores gastos com condomínio e demais despesas que compõe a variável, também sejam observados em relação ao comprometimento da renda.

Para a análise da (condição d) “Adensamento excessivo”, utilizou-se a variável 018 "Qual o número de moradores no domicílio (parentes e agregados)". Somente a partir da resposta a essa questão foi possível responder quantas UH estão nessa condição, porque todos os empreendimentos seguem um padrão de formação, com casas construídas de forma uníssona, compostas por dois cômodos destinados a servir como dormitórios. Tendo essa informação em vista, as famílias compostas por seis ou mais membros já estão nessa condição.

Sabe-se que é possível que outros cômodos venham a servir para a função supramencionada, inclusive se verificou em quais casos isso se aplica, a partir da variável 046 "Quantos cômodos estão servindo 
como dormitório para os moradores do seu domicílio atual?”, mas ao utilizar a sala, o banheiro ou a cozinha para dormir isso se enquadra como uma forma de inadequação das casas ao tamanho da família.

Para a análise da qualidade de vida urbana, selecionou-se do banco de dado um grupo de 21 questões que tratavam especificamente sobre as percepções dos beneficiários, conforme demonstrado no Quadro 1. Para que os cálculos pudessem ser realizados foi necessário subdividir as variáveis em 4 grandes grupos, da seguinte forma:

\section{Quadro 1 - Questões sobre a percepção dos moradores em 4 grandes grupos}

\begin{tabular}{|c|c|}
\hline GRUPOS & VARIÁVEIS \\
\hline \multirow{7}{*}{$\begin{array}{l}\text { Unidade } \\
\text { Habitacional }\end{array}$} & V018 - Qual o número de moradores no domicílio (parentes e agregados) \\
\hline & V060 - A nossa casa é muito pequena. \\
\hline & V059 - Os cômodos (peças) da casa são bem distribuídos. \\
\hline & V056 - A nossa casa é bem iluminada \\
\hline & V057 - Não temos problemas graves de umidade (ou goteira) \\
\hline & V058 - A temperatura da nossa casa é desagradável (muito quente ou muito fria) \\
\hline & V061- Estamos muito satisfeitos com a nossa casa. \\
\hline \multirow{4}{*}{ Vizinhança } & V062 - Nós temos relações muito boas com nossos vizinhos \\
\hline & V063 - Aqui no bairro tem muito problema de violência. \\
\hline & $\begin{array}{c}\text { V065 - Aqui no bairro teve gente fazendo trabalho social (ações de caráter informa- } \\
\text { tivo e educativo, que promovam o exercício da cidadania e favoreçam a organização } \\
\text { e a gestão comunitária dos espaços comuns). }\end{array}$ \\
\hline & V066 - Estamos muito satisfeitos com a nossa vizinhança. \\
\hline \multirow{6}{*}{ Localização } & $\begin{array}{l}\text { V064 - Aqui perto tem áreas de lazer para as crianças brincarem (quadra esportiva, } \\
\text { parque infantil, centro comunitário etc.). }\end{array}$ \\
\hline & V067 - Aqui perto tem posto de saúde ou hospital. \\
\hline & V069 - Aqui perto é fácil de pegar transporte público. \\
\hline & V068 - É muito difícil conseguir uma vaga numa escola próxima. \\
\hline & V070 - Nós demoramos muito tempo para ir e voltar do trabalho (ou da escola). \\
\hline & V071 - Estamos muito satisfeitos com a localização da nossa casa. \\
\hline
\end{tabular}




\begin{tabular}{|c|c|}
\hline GRUPOS & VARIÁVEIS \\
\hline \multirow{5}{*}{ Gastos mensais } & V072 - Quando mudamos para cá passamos a gastar muito mais com transportes. \\
\hline & $\begin{array}{l}\text { V073 - Nesta nova casa gastamos menos de aluguel (ou prestação) do que gastáva- } \\
\text { mos antes. }\end{array}$ \\
\hline & V074 - As contas de água, luz e condomínio são muito altas. \\
\hline & V075 - Estamos muito satisfeitos com a nova moradia. \\
\hline & V076 - Mudar para essa nova moradia fez nossa vida melhorar. \\
\hline
\end{tabular}

Fonte: Banco de dados da Pesquisa de Satisfação do MCMV (2014).

\section{CONCLUSÕES}

É nesse espaço marcado pela desigualdade econômica e geográfica, regulado pelo Estado e pelos setores privados, que os indivíduos ainda que formalmente inseridos no mercado de trabalho, não conseguem adquirir a casa própria. Diante disso, o Estado, no exercício de sua função, de proporcionar as condições mínimas de reprodutibilidade da força de trabalho e, perpetuação da vida urbana, cria políticas habitacionais, a fim de oportunizar a aquisição de domicílios a quem não consegue comprar.

Entretanto, essas políticas se demonstraram ineficientes na minimização do déficit habitacional, porque em todos os casos não incidiu prioritariamente sobre as camadas sociais em maior vulnerabilidade social. Além disso, a análise dos resultados apresentou taxas de inadimplência em todos os programas mais recentes, demonstrando que algumas famílias não conseguiam pagar taxas obrigatórias, por isso e outros motivos, abandonavam seus domicílios, retornando assim, às condições de habitabilidade ainda mais precária.

Vários dos programas possuíram como parâmetro de criação os resultados alcançados por programas anteriores. Esse foi o caso do MCMV, que previa em sua organização teórica (referente a primeira fase) a criação de 1 milhão de moradias. Entretanto, somente a menor parcela das casas (400 mil unidades) foi destinada ao atendimento do grupo que mais precisava de habitação, que são as famílias que possuem renda bruta mensal de até 3 salários mínimos e que compõe $90 \%$ do Déficit Habitacional. $O$ outro cenário de criação e implementação do Programa MCMV foi a crise do subprimes que teve início em 2007 e em 2008 começou a afetar a economia nacional brasileira.

Diante do histórico alinhavado pelas políticas habitacionais, foi possível a análise do MCMV e, posterior, manipulação do banco de dados gerados pela Pesquisa de Satisfação dos Beneficiários do programa Minha Casa Minha Vida (2014), tendo como parâmetro de avaliação a qualidade de vida urbana e o déficit habitacional dos beneficiários. Utilizou-se o método quantitativo, por intermédio das variáveis escolhidas que pudessem auxiliar no cumprimento dos objetivos definidos.

A partir da seleção das variáveis que poderiam analisar as condições que compõe o déficit os cálculos demonstraram o seguinte resultado: a primeira condição, não foi investigada. A segunda 
condição, coabitação familiar (quando existe mais de uma família convivente, residindo na mesma UH), ocorre com uma porcentagem muito pequena dos beneficiários, são 4,3\% que vivem com mais uma família e $0,1 \%$ vive com mais duas famílias. Então é possível inferir que após o recebimento da UH do MCMV a maioria das famílias não vive em situação de coabitação. Sobre a pequena parcela que vive com uma formação familiar secundária, é importante salientar que morar dessa maneira pode ser parte de uma escolha individual das famílias.

Para responder a terceira condição que classifica como déficit habitacional as famílias que utilizam $30 \%$ ou mais de suas rendas totais para o pagamento do aluguel, realizou-se uma série de análises e, constatou-se a partir dos gráficos gerados sobre a renda bruta familiar que a maioria ainda se encontra na faixa de renda mais baixa, recebendo até no máximo 2 salários mínimos, a segunda maior parcela de entrevistados recebe de $1 / 2$ a no máximo 1 salário mínimo e a maior quantidade de famílias nessa faixa salarial é composta por 3 ou 4 membros.

As análises demonstraram que os ganhos das famílias são baixos em relação ao custo de vida, contudo não é possível verificar se após o recebimento da moradia houve alguma mobilidade social de acréscimo ou decréscimo. Mas pode-se inferir que a maior parte dos moradores ainda se enquadra no faixa 1 do MCMV, afinal, recebem até no máximo 3 salários mínimos. Mas essa condição também não incide sobre as famílias após o recebimento da UH do MCMV, porque a grande maioria, 93,6\%, gasta com aluguel até no máximo $30 \%$ da renda familiar.

Como este trabalho considerou o indicador de avaliação "c" impreciso para avaliar a condição dos gastos familiares, por levar em consideração somente o valor do aluguel, foi proposto que os valores gastos com: condomínio, água e luz fossem avaliados similarmente, porque são gastos mensais em que o não pagamento acarreta sansões semelhantes à inadimplência do aluguel. Ao gerar as tabelas desses gastos verificou-se que eles também não comprometem mais que $30 \%$ da renda, pois a maior parcela, 92,6\%, compromete no máximo essa porcentagem de $30 \%$ com os gastos descritos e mesmo com a análise associativa entre os gastos mensais com aluguel somados ao de água, luz e condomínio ainda não ultrapassam $30 \%$ das receitas totais para a maior parte das famílias.

A última condição analisada, sobre adensamento excessivo, segundo a FJP as famílias que estão nessa situação são aquelas que possuem três ou mais membros, utilizando o mesmo cômodo como dormitório permanente. Essa foi a única condição na qual valores encontrados são mais expressivos: constatou-se que $25,6 \%$ das famílias encontram-se nessa situação, entretanto a maior parcela, $74,3 \%$, possui uma quantidade de membros que é considerada ideal para a quantidade de cômodos já dispostos para ser usados como dormitório, ou seja, de 1 a 4 membros.

Optou-se por utilizar o termo qualidade de vida urbana, pois como se demonstrou, apesar de se tratar de um termo abstrato, por intermédio da manipulação das 21 variáveis que analisam a percepção dos moradores é possível dar materialidade a esse termo. Para que os cálculos e análises descritivas fossem realizados foi necessário dividir as variáveis em três categorias menores que foram denominadas como: i) qualidade da habitação; ii) qualidade urbana e iii) vulnerabilidade social e para a realização dos cálculos, utilizou-se a subdivisão em 4 grandes grupos, que posteriormente foram enquadradas nessas 3 categorias. 
Sobre a UH constatou-se que as casas são pequenas, mas os cômodos são bem distribuídos. A iluminação é boa e não há muitos problemas com umidade (ou goteiras), mas a temperatura não é adequada, porque ou a casa é muito fria ou muito quente. Apesar disso, os moradores, em sua maioria, estão satisfeitos com suas casas. No que tange a vizinhança, constatou-se uma grande porcentagem de percepção de violência no bairro e pouco trabalho social realizado por pessoas com a intenção de fomentar a vida em comunidade. Entretanto, a maioria dos entrevistados sente-se satisfeito com seus vizinhos e comunga de uma boa relação com eles.

Ao analisar as variáveis sobre a localidade constatou-se que faltam alguns equipamentos públicos, como parques infantis e centros médicos para grande parte dos moradores, porém, o transporte público é acessado pela maioria com facilidade. Por falta de escola ou por pouca quantidade de vagas oferecidas em cada instituição os moradores têm dificuldade para matricular seus filhos em escolas próximas a suas casas, por isso gastam muito tempo cotidianamente para ir estudar ou trabalhar. Todavia, a grande maioria está satisfeita com a localidade de suas casas.

Sobre os gastos familiares mensais, os dados demonstraram que a maioria dos moradores passou a gastar mais com transporte, em contraposição passaram a gastar menos com aluguel (ou prestação) da casa. Em relação às outras contas fixas da casa (água, luz e condomínio) responderam que são custos altos, mas que estão felizes e satisfeitos com a nova casa.

Conclui-se, a partir da percepção dos próprios moradores que suas vidas melhoraram após o recebimento da UH do Programa MCMV, pois eles não vivem mais em casas construídas de forma precária. Em relação a casa, o único ponto negativo apontado pela maioria é a temperatura das UH e o tamanho. Não vivem em situação de coabitação familiar e, as poucas famílias que vivem com outros grupos familiares, não possuem a intenção de constituir novo domicílio. Sobre os gastos, apesar de as contas fixas da casa serem consideradas altas, elas não ultrapassam $30 \%$ da renda familiar, além disso, os moradores passaram a gastar menos com aluguel (ou prestação) da casa, o que levou a um aumento do poder aquisitivo para as famílias de classe baixa.

Apesar de terem facilidade de acessar o transporte público, passaram a gastar mais para se transportar. Isso indica que os conjuntos estão afastados dos serviços que os moradores necessitam no local de moradia, grande parte dos entrevistados respondeu não ter acesso a parques de lazer para as crianças, centros médicos e escolas. Por isso gastam cotidianamente muito tempo para se transportar indo para escola ou para o trabalho.

Ainda assim, sobre a localidade a grande maioria dos entrevistados demonstra estar satisfeita. Apesar de considerarem as UH pequenas, a maior parte das famílias não vive em situação de adensamento excessivo, consideram os cômodos bem distribuídos, isto é, estão satisfeitos com as condições da nova casa e sentem-se mais felizes após terem sido beneficiados pelo MCMV.

Apesar das percepções positivas dos beneficiários verificou-se uma falta de qualidade da habitação por meio dos dados que demonstram que as casas são pequenas e que possuem temperaturas inadequadas e uma baixa qualidade urbana de acesso aos equipamentos públicos, como escolas, equipamentos de lazer para as crianças, centros de saúde para grande parte dos entrevistados, além disso, a maioria respondeu que demora muito tempo para ir trabalhar ou estudar, isso carac- 
teriza uma situação de periferização, na medida em que os indivíduos não conseguem emprego próximo a suas moradias. Dentre os objetivos secundários analisados constatou-se, também, uma situação de vulnerabilidade social quando os dados demonstraram que os moradores percebem um alto nível de violência em seus bairros.

Por fim, entende-se que ao receber a casa do MCMV as famílias deixam de estar em condições semeIhantes às que estavam antes, no que tange ao Déficit Habitacional, pois se constatou que nenhuma das condições do indicador ocorre na maioria da amostra, somente a última condição, sobre adensamento excessivo ocorre em uma quantidade substancial de moradores. Contudo, constitui-se bastante inferior à metade dos beneficiários, mas em relação à qualidade de vida urbana constatou-se falta de qualidade de habitação, baixa qualidade urbana, situação de periferização e vulnerabilidade social.

Isso ocorre porque como se demonstrou no decorrer da dissertação o PMCMV está associado ao Programa de Aceleramento Econômico (PAC) e ao ser implementado deixou de tomar como eixo central as discussões relacionadas ao acesso a moradia pela população mais pobre e voltou-se a resolução de uma crise de caráter internacional. Diante da crise, o programa apresentou resultados positivos e gerou uma quantidade massiva de unidades habitacionais.

Todavia, seguindo a lógica de produção do mercado que possui como eixo primordial a maximização dos lucros, em função disso, houve sacrifícios que recaíram sobre as famílias beneficiárias, no que tange o direito à habitação, no sentido mais amplo que essa palavra compreende, como espaço que não serve somente a moradia, pois está incumbida da função de fomentar a vida social e do coletivo, possibilitando assim o direito à cidade de maneira ampla.

\section{REFERÊNCIAS}

AMORE, Caio Santo. “Minha Casa Minha Vida” para iniciantes. In: RUFINO, Maria Beatriz Cruz; SHIMBO, Lucia Zanin; AMORE, Caio Santo, Minha Casa... E a Cidade? Rio de Janeiro: Letra Capital, 2015. p. 11-28.

ARAGÃO, Thêmis Amorim; ADAUTO, Lucio Cardoso; JAENISCH, Samuel Thomas. 22 anos de política habitacional no Brasil: da euforia à crise. Rio de Janeiro: Letras Capital: Observatório das Metrópoles, 2017.

\section{ARANTES, Pedro Fiori; FIX, Mariana. Como o governo Lula pretende resolver o problema da} habitação: alguns comentários sobre o pacote habitacional Minha Casa, Minha Vida. São Paulo: Boitempo 2009.

AZEVEDO, Sérgio. Vinte e dois anos de política de habitação popular (1964-86): Criação, trajetória e extensão do BNH. Rev. Administração Pública, Rio de Janeiro, v. 22, n. 4, p. 107-119, out./dez. 1988 
AZEVEDO, Paulo Roberto. Passageiros da ilegalidade: história de uma luta pela moradia. Cascavel: Udunioeste, 2002.

AZEVEDO, Sérgio; RIBEIRO, Luiza Cezar de Queiroz. A produção da moradia nas grandes cidades: dinâmica e impasses. In: RIBEIRO, Luiz Cesar de Queiroz;

AZEVEDO, Sérgio (org.). A crise da moradia nas grandes cidades: da questão da habitação à reforma urbana. Rio de Janeiro: UFRJ, 1996. p. 13-32.

BOLAFFI, Gabriel. Habitação e urbanismo: o problema e o falso problema. In: MARICATO, Ermínia. A produção capitalista da casa (e da cidade) no Brasil industrial. São Paulo: Alfa-Ômega, 1979. p. 37-70.

BONDUKI, Nabil. Origens da habitação social no Brasil: arquitetura moderna, lei do inquilinato e difusão da casa própria. 4. Ed. São Paulo: Estação da Liberdade, 2014.

BORÇA, Gilberto Rodrigues; TORRES, Ernani Teixeira. Analisando a crise do analisando a crise do subprime. Revista Do BNDES, Rio de Janeiro, v. 15, n. 30, p. 129-159, dez. 2008.

BRASIL. Lei n. 10.406 de 10 de janeiro de 2002. Código Cível. Disponível em: http://www.planalto. gov.br/ccivil_03/leis/2002/L10406.htm. Último acesso: 7 jan. de 2018.

\section{CARNEIRO, Dionísio Dias; VALPASSOS, Marcus Vinicius Ferrero. Financiamento à habitação e} instabilidade econômica: experiências passadas, desafios e propostas para a ação futura. Rio de Janeiro: FGV, 2003.

CARVALHO, Sonia Nahas de. A política nacional de habitação e ação do estado. São Paulo em Perspectiva, v. 5, n. 4, out./dez. 1991. p. 50-59.

\section{FIX, M. Financeirização e transformações recentes no circuito imobiliário no}

Brasil. 2011. Tese (Doutorado em Desenvolvimento Econômico) - Programa de Pós-Graduação em Desenvolvimento Econômico, Universidade Estadual de Campinas, Campinas, 2011.

FJP - Fundação João Pinheiro. Centro de Estatística e informações. Déficit Habitacional no Brasil 2011-2012. Belo Horizonte: Centro de Estatística e Informações, 2015.

LAGO, Luciana Corrêa. A produção autogestionária do habitat popular e a requalificação da vida urbana. In: ARAGÃO, Thêmis Amorim; ADAUTO, Lucio Cardoso; JAENISCH, Samuel Thomas. 22 anos de política habitacional no Brasil: da euforia à crise. Rio de Janeiro: Letras Capital; Observatório das Metrópoles, 2017. 
MARICATO, Ermínia. Política habitacional no regime militar: do milagre brasileiro à crise econômica. Rio de Janeiro: Vozes, 1987.

MARICATO, Ermínia. Urbanismo na periferia do mundo globalizado. São Paulo perspectiva, São Paulo, v. 14, n. 4, 2000.

PESQUISA de satisfação dos beneficiários do Programa Minha Casa Minha Vida - Brasília, DF: MCIDADES, SNH; SER-PR; IPEA, 2014. 


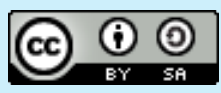

Este artigo é licenciado na modalidade acesso abertosob a Atribuição-Compartilhalgual CC BY-SA 